\title{
Qualidade microbiológica e microscópica de polpas de frutas congeladas comercializadas no município de Limoeiro do Norte- CE
}

Microbiological and microscopic quality of frozen fruit pulp sold in the city of Limoeiro do NorteCE

\section{Calidad microbiológica y microscópica de pulpa de fruta congelada vendida en la ciudad de Limoeiro do Norte- CE}

Thays Lima Fama Guimarães

ORCID: https://orcid.org/0000-0003-3644-8811 Instituto Federal de Educação, Ciência e Tecnologia do Ceará, Brasil E-mail: thaysfama@hotmail.com

Virna Luiza de Farias

ORCID: https://orcid.org/0000-0003-1459-7525 Instituto Federal de Educação, Ciência e Tecnologia do Ceará, Brasil E-mail: virna@ifce.edu.br

Érica Maria Gomes Vidal

ORCID: https://orcid.org/0000-0002-5417-7739 Instituto Federal de Educação, Ciência e Tecnologia do Ceará, Brasil E-mail: ericamgvidal@gmail.com

Vandesonia Maria de Sousa Oliveira

ORCID: https://orcid.org/0000-0001-7913-0892 Instituto Federal de Educação, Ciência e Tecnologia do Ceará, Brasil E-mail: vandesonia@hotmail.com

Germana Conrado de Souza

ORCID: https://orcid.org/0000-0002-5297-6465 Instituto Federal de Educação, Ciência e Tecnologia do Ceará, Brasil E-mail: germanaconrado@ifce.edu.br

Francisco Jorge Nogueira de Moura ORCID: https://orcid.org/0000-0001-9463-6410 Instituto Federal de Educação, Ciência e Tecnologia do Ceará, Brasil E-mail: jorgenogueira@ifce.edu.br

\begin{abstract}
Resumo
O objetivo deste trabalho foi avaliar a qualidade higiênico-sanitário de polpas de frutas congeladas comercializadas na cidade de Limoeiro do Norte-CE. Foram analisados dois lotes de polpas de frutas congeladas dos sabores acerola, caju e goiaba, de oito marcas comerciais (A, B, C, D, E, F, G e H), totalizando 48 amostras, adquiridas no comércio local de Limoeiro do Norte, de julho de 2019 a fevereiro de 2020. As análises realizadas foram: microbiológicas (coliformes totais, coliformes termotolerantes, Escherichia coli, Salmonella sp. e bolores e leveduras) e microscópicas (estranhas leves e pesadas). Os resultados obtidos indicaram que as amostras dos Lotes 1 e 2 não estavam de acordo com a Instrução Normativa $N^{\circ} 60$ de 23 de dezembro de 2019 da ANVISA. Já para a Instrução Normativa N $^{\circ} 01$ de 07 de janeiro de 2000 do MAPA, no Lote 1 e Lote 2, 41,6\% e 37,5\% das amostras, respectivamente, estavam em desacordo. Todas as amostras apresentaram ausência de salmonela, mas para coliformes termotolerantes houve crescimento de até $1,5 \times 10^{2} \mathrm{UFC}^{-1}$. A marca D foi a única que não apresentou nenhum crescimento microbiano nas polpas de acerola, caju e goiaba. Quanto às análises macroscópicas, os fragmentos encontrados nas amostras foram de metal, plásticos coloridos e fio têxtil. As marcas E e H não apresentaram sujidades. Já as marcas B e D apresentaram maior quantidade de matéria estranha. Esse estudo mostrou que as indústrias analisadas necessitam implementar um programa padronizado de qualidade, pois houve variação nos resultados microbiológicos e de microscopia.
\end{abstract}

Palavras-chave: Polpas de frutas; Matéria estranha; Microrganismo.

\section{Abstract}

The objective of this work was to evaluate the hygienic-sanitary quality of frozen fruit pulps sold in the city of Limoeiro do Norte- CE. Two batches of acerola, cashew and guava frozen fruit pulps from eight commercial brands (A, B, C, D, E, F, G and H), totaling 48 samples, purchased at the local store of Limoeiro do Norte, from July 2019 to February 2020, were analyzed. The analyzes carried out were: microbiological (total and thermotolerant coliforms, Escherichia coli, Salmonella sp. and molds and yeasts) and microscopic (light and heavy foreign matter). The results 
indicated that the samples from Batch 1 and 2 were not in accordance with the Normative Instruction 60 of December 23, 2019 of ANVISA. As for Normative Instruction 01 of January 7, 2000 from MAPA, for fruit pulps in Batch 1 and Batch 2, $41.6 \%$ and $37.5 \%$ of the samples, respectively, were in disagreement. All samples showed no salmonela, but for thermotolerant coliforms there was growth of up to $1,5 \times 10^{2} \mathrm{CFU} \mathrm{g}{ }^{-1}$. The brand D was the only one that did not show any microbial growth in the acerola, cashew and guava pulps. As for macroscopic analyzes, the fragments found were metal, colored plastics and textile thread. The brands E and $\mathrm{H}$ showed no dirt. The brands B and D, on the other hand, had the higher amount of foreign matter. This study showed that the analyzed industries need to implement a standardized quality program, as there was variation in the microbiological and microscopic results.

Keywords: Fruit pulp; Foreign matter; Microorganism.

\section{Resumen}

El objetivo de este trabajo fue evaluar la calidad higiénico-sanitaria de las pulpas de frutas congeladas comercializadas en la ciudad de Limoeiro do Norte-CE. Se analizaron dos lotes de pulpas de frutas congeladas de sabores de acerola, anacardo y guayaba, de ocho marcas comerciales (A, B, C, D, E, F, G y H), totalizando 48 muestras, adquiridas en el comercio local de Limoeiro do Norte, de julio de 2019 a febrero de 2020. Los análisis realizados fueron: microbiológicos (coliformes totales, coliformes termotolerantes, Escherichia coli, Salmonella sp. y mohos y levaduras) y microscópicos (extraños ligeros y pesados). Los resultados obtenidos indicaron que las muestras de los Lotes 1 y 2 no cumplieron con la Instrucción Normativa 60 de ANVISA del 23 de diciembre de 2019. En cuanto a la Instrucción Normativa MAPA 01 del 7 de enero de 2000, en el Lote 1 y Lote 2, $41.6 \%$ y 37.5\% de las muestras, respectivamente, estaban en desacuerdo. Todas las muestras mostraron ausencia de salmonella, pero para los coliformes termotolerantes hubo un crecimiento de hasta $1.5 \times 10^{2} \mathrm{UFC} \mathrm{g}^{-1}$. La marca D fue la única que no mostró ningún crecimiento microbiano en pulpas de acerola, anacardo y guayaba. En cuanto a los análisis macroscópicos, los fragmentos encontrados en las muestras fueron metal, plásticos coloreados e hilo textil. Las marcas E y H no mostraron suciedad. Las marcas B y D, por otro lado, tenían una mayor cantidad de materia extraña. Este estudio mostró que las industrias analizadas necesitan implementar un programa de calidad estandarizado, ya que hubo variación en los resultados microbiológicos y microscópicos.

Palabras clave: Pulpa de frutos; Materias extrañas; Microorganismos.

\section{Introdução}

A produção de frutas é um setor que vem crescendo mundialmente, e nesse contexto, o Brasil se destaca como um dos maiores países produtores. De acordo com dados da Food and Agriculture Organization (2018), em 2017 o Brasil foi o terceiro maior produtor mundial de frutas, com 42,2 milhões de toneladas.

A polpa é um dos principais produtos industriais das frutas brasileiras. O processamento de frutas para a produção de polpas é uma importante atividade agroindustrial, agregando valor, minimizando perdas, aumentando sua vida útil. Além disso, a polpa pode ser encontrada em diferentes épocas do ano, podendo substituir a fruta in natura no preparo de sucos, néctares, doces, geleias, sorvetes (Pereira et al., 2006). O Ministério da Agricultura, Pecuária e Abastecimento (MAPA), responsável por regulamentar os padrões de identidade e qualidade (Brasil, 2000), define "polpa de frutas como produto não fermentado, não concentrado, não diluído, obtido a partir de frutos polposos, através de um processo técnico adequado, com um teor mínimo de sólidos totais, da parte comestível da fruta".

Alguns dos métodos de conservação para aumentar a vida útil das polpas são a pasteurização, a adição de aditivos químicos e o congelamento. Dentre essas alternativas, o congelamento é o mais utilizado, mas falha nessa técnica como o rompimento da cadeia do frio, pode ocasionar crescimento microbiano, prejudicando a qualidade do produto (Pereira et al., 2006).

As análises microbiológicas no produto são fundamentais para verificar as condições higiênicas em que o alimento foi processado e a sua qualidade, além de estimar o risco que pode oferecer a saúde do consumidor, dependendo do microrganismo responsável pela contaminação (Franco \& Landgraf, 2003). Por isso, existem dois órgãos regulamentadores que estabelecem padrões microbiológicos para polpas de frutas.

A Instrução Normativa $\mathrm{N}^{\circ} 01$ de 07 de janeiro de 2000 do MAPA (Brasil, 2000) determina para polpas de frutas in natura o limite máximo de $5 \times 10^{3} \mathrm{UFC} \mathrm{g}^{-1}$ para contagem de bolores e leveduras, e $2 \times 10^{3} \mathrm{UFC} \mathrm{g}^{-1} \mathrm{em}_{\text {polpas de frutas }}$ tratadas termicamente. Já coliformes termotolerantes não devem ultrapassar 1,0 NMP g ${ }^{-1}$, e Salmonella sp. deve ser ausente em 
$25 \mathrm{~g}$ do produto. A Agência Nacional de Vigilância Sanitária (ANVISA), por meio da RDC N 331 de 23 de dezembro de 2019 (Brasil, 2019), dispõe sobre os padrões microbiológicos de alimentos e sua aplicação, enquanto a Instrução Normativa $\mathrm{N}^{\circ}$ 60 de 23 de dezembro de 2019 a complementa, estabelecendo as listas de padrões microbiológicos para alimentos. Nesta última, encontram-se os seguintes padrões microbiológicos para polpas de frutas: ausência de Salmonella em $25 \mathrm{~g}$ do produto, até $10 \mathrm{UFC} \mathrm{g}^{-1}$ de Escherichia coli e $10^{3} \mathrm{UFC} \mathrm{g}^{-1}$ de bolores e leveduras.

Quanto às matérias estranhas, de acordo com o exigido na legislação que estabelece o Regulamento Técnico de Boas Práticas de Fabricação para estabelecimentos produtores/industrializadores de frutas e/ou hortaliças em conserva e a lista de verificação das boas práticas de fabricação para estabelecimento produtores/industrializadores de frutas e/ou hortaliças em conserva (Brasil, 2002), polpas de frutas não devem conter terra, sujidades, parasitas, fragmento de insetos e pedaços não comestíveis da fruta ou planta.

A RDC N ${ }^{\circ} 14$ de 28 de março de 2014, que dispõe sobre as matérias estranhas macroscópicas e microscópicas em alimentos e bebidas e seus limites de tolerâncias, define matéria estranha como "qualquer material não constituinte do produto associado a condições ou práticas inadequadas na produção, manipulação, armazenamento ou distribuição" (Brasil, 2014).

As sujidades podem ser classificadas como "leves" ou "pesadas" dependendo da sua densidade e do meio de flutuação pelo qual são separadas. As matérias estranhas leves, devido às suas características lipofílicas, são separadas por flutuação em mistura líquida de água e óleo. Já as matérias estranhas pesadas, sendo sujidades formadas por elementos mais pesados que os constituintes dos alimentos são separadas por sedimentação (Ziobro, 2000).

As frutas utilizadas para elaboração das polpas devem ser de boa qualidade a fim de garantir a segurança do consumidor, o que é um desafio, pois são propicias à contaminação por insetos, que podem ocasionar sua deterioração. As polpas de frutas de goiaba, acerola e caju são fáceis de serem encontradas no comércio de Limoeiro do Norte-CE, pois essas frutas podem ser produzidas na própria região.

Assim, visando verificar se as polpas de frutas ofertadas no comércio são seguras para o consumidor, o objetivo desse trabalho foi avaliar a qualidade microbiológica e microscópica de polpas de frutas de goiaba, acerola e caju comercializadas em Limoeiro do Norte-CE, verificando sua adequação às legislações vigentes.

\section{Metodologia}

\section{Obtenção das amostras}

O presente estudo trata-se de uma pesquisa experimental com abordagem qualitativa e quantitativa, que avaliou diferentes variáveis em polpas de frutas, por meio das análises dos dados numéricos e interpretação dos dados obtidos (Gil, 2002).

As polpas de frutas congeladas industrializadas utilizadas neste experimento foram adquiridas em supermercados da cidade de Limoeiro do Norte-Ceará, todas as polpas tinham selo de Inspeção Federal do MAPA. As 48 amostras foram constituídas de 3 sabores (acerola, caju e goiaba) e 8 marcas (A, B, C, D, E, F, G e H), em dois lotes diferentes de cada polpa. No momento da compra, as polpas foram acondicionadas em caixa isotérmica de isopor e transportadas para a Planta Piloto de Frutas e Hortaliças do IFCE Campus Limoeiro do Norte, para posteriormente serem realizadas as análises microbiológicas, microscópicas, no período de julho de 2019 a fevereiro de 2020.

\section{Análises microbiológicas}

As análises microbiológicas realizadas foram quantificação de coliformes totais e termotolerantes, bolores e leveduras, pesquisa de Escherichia coli e de Salmonella sp., executadas de acordo com as metodologias de Silva et al. (2017). 
Ainda de acordo com as metodologias utilizadas, as amostras foram descongeladas, homogeneizadas e deixadas à temperatura de $26^{\circ} \mathrm{C}$ antes do início das análises.

\section{Preparo das amostras}

Pesou-se $10 \mathrm{~g}$ de cada polpa de fruta em um frasco contendo $90 \mathrm{~mL}$ de solução salina $0,85 \%$ estéril (diluição $10^{-1}$ ). Homogeneizou-se e a partir dessa diluição preparou-se as demais diluições decimais seriadas até $10^{-3}$.

\section{Determinação de coliformes totais e termotolerantes}

Inoculou-se $1 \mathrm{~mL}$ de cada diluição em três tubos de Caldo Lactosado (CL), contendo tubo de Duhran invertido (teste presuntivo). Os tubos foram incubados em estufa bacteriológica a $35{ }^{\circ} \mathrm{C}$ por $24-48$ horas. Dos tubos com crescimento de microrganismos (turvação e formação de gás), transferiu-se uma alçada de cada cultura para tubos de Caldo Verde Brilhante (BVB), que foram incubados em estufa bacteriológica a $35{ }^{\circ} \mathrm{C}$ por $24-48$ horas. A partir dos tubos confirmativos foi transferida uma alçada para tubo de Caldo EC, que foi incubado em banho-maria a $45{ }^{\circ} \mathrm{C}$ por 24 horas, e verificou-se a ocorrência de crescimento. Determinou-se o Número Mais Provável (NMP g ${ }^{-1}$ ) em uma tabela de NMP apropriada às diluições inoculadas.

\section{Pesquisa de E.coli}

De cada tubo de Caldo EC com produção de gás, estriou-se uma alçada da cultura em placas de Ágar Eosina Azul de Metileno (EMB) e as placas foram incubadas a $35^{\circ} \mathrm{C}$ por 24 horas. Verificou-se se houve ou não o crescimento de colônias típicas de E. coli (nucleadas com centro preto, com brilho metálico).

\section{Pesquisa de Salmonella sp.}

Pesou-se $25 \mathrm{~g}$ da polpa de fruta em um frasco de $225 \mathrm{~mL}$ de Caldo Lactosado e incubou-se a $35^{\circ} \mathrm{C}$ por 24 horas. Em seguida, foi inoculado $1 \mathrm{~mL}$ em $10 \mathrm{~mL}$ de Caldo Rappaport-Vassiliadis (RV) e incubou-se a $35{ }^{\circ} \mathrm{C}$ por 24 horas. O plaqueamento seletivo e diferencial foi realizado nos meios Ágar Entérico de Hectoen (HE) e Ágar de Desoxicolato Lisina Xilose (XLD). As placas foram incubadas a $35{ }^{\circ} \mathrm{C}$ por 24 horas. Após esse tempo, verificou-se se houve ou não o desenvolvimento de colônias típicas de Salmonela.

\section{Bolores e leveduras}

Para contagem de bolores e leveduras, foi utilizado o método de plaqueamento direto em superfície (Spread Plate) das diluições $10^{-1}, 10^{-2}$ e $10^{-3}$ das amostras em solução salina, em meio Ágar Batata Dextrose acidificado com $1 \%$ de solução de ácido lático $1 \%$, inoculando-se alíquotas de $0,1 \mathrm{~mL}$ nas placas, que foram incubadas a $22{ }^{\circ} \mathrm{C}$ por 3 a 5 dias. Decorrido esse tempo, observou-se se houve crescimento nas placas. Calculou-se o número de Unidade Formadora de Colônia (UFC) por grama de amostra.

\section{Método de flutuação para substâncias estranhas leves}

A um frasco de armadilha de Wildman de $1000 \mathrm{ml}$, adicionou-se $100 \mathrm{~g}$ de polpa de fruta, $450 \mathrm{~mL}$ de água e $17,5 \mathrm{~mL}$ de óleo de rícino. Inclinou-se o frasco a $45^{\circ}$ e movimentou-se o êmbolo para baixo e para cima, misturando bem óleo, a água e a substância alimentícia. Depois adicionou-se água tépida, até quase o gargalo. Agitou-se a mistura novamente e a deixou em repouso. Quando o óleo ascendeu, adicionou-se mais água quente até o nível do óleo alcançar o topo do gargalo do frasco. Ergueu-se a vareta até a rolha separar o óleo e certa quantidade de água. Despejou-se o óleo, a água e os resíduos de polpa separados no gargalo do frasco para o béquer. Lavou-se a boca do Erlenmeyer com um jato de água, recebendo essa água no 
mesmo béquer anteriormente citado. Adicionou-se mais $17,5 \mathrm{~mL}$ de óleo no frasco, agitou-se e procedeu-se de maneira idêntica à anterior. Vedou-se um funil de Buchner com papel filtro e colocou sobre o funil sobre um frasco de kitassato, ligado a uma bomba vácuo. Filtrou-se o líquido hidro-oleoso, contendo resíduos de alimento, pelo funil de Buchner, de maneira a reter o resíduo do alimento sobre o papel, de acordo com Association of Official Analytical Chemistry (2007). Colocou-se o papel de filtro contendo o resíduo alimentício em uma placa de Petri e observou-o em estereoscópio. Contou-se o número de sujidades presentes, e em caso de dúvida quanto à identificação da sujidade, observou-se também em microscópio.

\section{Método de decantação para substâncias estranhas pesadas}

Utilizou-se o resíduo do processo do método de flutuação que permaneceu no frasco. Transferiu-se o material para um béquer de $1000 \mathrm{~mL}$. Encheu-se o béquer de água até quase a borda. Agitou-se o conteúdo e deixou-o decantar cerca de um oitavo. Tornou-se a encher o béquer e repetiu-se a operação por quatro vezes. Filtrou-se o conteúdo do béquer em um funil de Buchner, adaptado a um kitassato ligado à bomba de vácuo, de acordo com Association of Official Analytical Chemistry (2007). Observou-se o resíduo retido no papel de filtro em estereoscópio, com aumento de 30 ×, e também se transferiu as sujidades para lâminas de vidro, cobertas com lamínulas para visualização em microscópio óptico com aumento de $400 \times$.

\section{Resultados e Discussão}

\section{Análises microbiológicas}

Nas Tabelas 1 e 2 estão apresentados os resultados das análises microbiológicas das polpas de frutas das diferentes marcas analisadas em comparação com os padrões das duas legislações vigentes, sendo uma da ANVISA e a outra do MAPA.

A Instrução Normativa $\mathrm{N}^{\circ} 60$ de 23 de dezembro de 2019 da ANVISA estabelece padrões microbiológicos para alimentos destinados ao consumo humano, enquanto a Instrução Normativa $\mathrm{N}^{\circ} 01$ de 07 de janeiro de 2000 do MAPA regulamenta os padrões de identidade e qualidade para polpa de fruta, onde a primeira permite avaliar se as amostras trazem algum risco à saúde do consumidor, e segunda, as condições higiênico-sanitárias nas quais foi elaborado esse produto.

A Instrução Normativa $N^{\circ}$ 60, de 23 de dezembro de 2019 estabelece para polpas de frutas ausência de Salmonella sp., até $10 \mathrm{UFC}^{-1}$ de E. Coli e até $10^{3} \mathrm{UFC} \mathrm{g}^{-1}$ de bolores e leveduras. Já a Instrução Normativa $\mathrm{N}^{\circ} 01$ de 07 de janeiro de

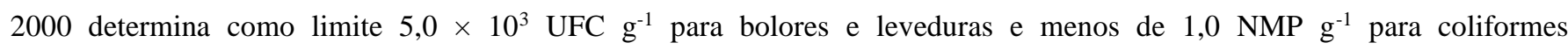
termotolerantes.

Avaliando os resultados das amostras do Lote 1 (Tabela 1) e comparando-os com os padrões estabelecidos na Instrução Normativa N N$^{\circ} 60$ (Brasil, 2019), verificou-se que 58\% das amostras não estavam no limite estabelecido para bolores e leveduras pela legislação. Mas para E. coli e Salmonella sp. todas as amostras se encontraram dentro dos padrões exigidos, pois em nenhuma das polpas foi detectado crescimento desses microrganismos.

Já comparando os mesmos resultados com os padrões exigidos pelo MAPA (Brasil, 2000), 41,6\% das amostras não se apresentaram de acordo quanto a bolores e leveduras, e 4,1\% para coliformes termotolerantes, sendo a polpa de goiaba da marca $\mathrm{E}$ a que apresentou maior contaminação. 
Tabela 1- Análises microbiológicas de polpas de frutas do Lote 1: coliformes totais, coliformes termotolerantes, pesquisa Escherichia coli, Salmonella sp., e bolores e leveduras.

\begin{tabular}{|c|c|c|c|c|c|c|}
\hline \multicolumn{7}{|c|}{ LOTE 1} \\
\hline Marca & Sabor & $\begin{array}{c}\text { Coliformes } \\
\text { totais } \\
\left(\mathrm{NMP} \mathrm{g}^{-1}\right)\end{array}$ & 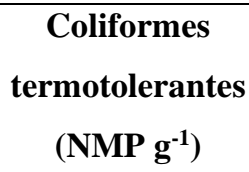 & $\begin{array}{c}\text { Pesquisa de } \\
\qquad \text { E. coli }\end{array}$ & Salmonella sp./25g & $\begin{array}{r}\text { Bolores e } \\
\text { leveduras } \\
\left(\mathrm{UFC} \mathrm{g}^{-1}\right)\end{array}$ \\
\hline A & Acerola & $<3,0$ & $<3,0$ & Ausência & Ausência & $1,8 \times 10^{4}$ \\
\hline A & Caju & $<3,0$ & $<3,0$ & Ausência & Ausência & $8,0 \times 10^{2}$ \\
\hline A & Goiaba & $<3,0$ & $<3,0$ & Ausência & Ausência & $4,2 \times 10^{4}$ \\
\hline B & Acerola & $<3,0$ & $<3,0$ & Ausência & Ausência & $3,1 \times 10^{3}$ \\
\hline B & Caju & $<3,0$ & $<3,0$ & Ausência & Ausência & $4,6 \times 10^{4}$ \\
\hline B & Goiaba & $2,3 \times 10$ & $<3,0$ & Ausência & Ausência & $<100$ \\
\hline $\mathrm{C}$ & Acerola & $<3,0$ & $<3,0$ & Ausência & Ausência & $2,0 \times 10^{3}$ \\
\hline $\mathrm{C}$ & Caju & $<3,0$ & $<3,0$ & Ausência & Ausência & $<100$ \\
\hline $\mathrm{C}$ & Goiaba & $<3,0$ & $<3,0$ & Ausência & Ausência & $3,4 \times 10^{4}$ \\
\hline $\mathrm{D}$ & Acerola & $<3,0$ & $<3,0$ & Ausência & Ausência & $<100$ \\
\hline $\mathrm{D}$ & Caju & $<3,0$ & $<3,0$ & Ausência & Ausência & $<100$ \\
\hline $\mathrm{D}$ & Goiaba & $<3,0$ & $<3,0$ & Ausência & Ausência & $<100$ \\
\hline $\mathrm{E}$ & Acerola & $<3,0$ & $<3,0$ & Ausência & Ausência & $1,2 \times 10^{4}$ \\
\hline $\mathrm{E}$ & Caju & $<3,0$ & $<3,0$ & Ausência & Ausência & $<10$ \\
\hline $\mathrm{E}$ & Goiaba & $1,1 \times 10^{3}$ & 3,6 & Ausência & Ausência & $1,2 \times 10^{5}$ \\
\hline $\mathrm{F}$ & Acerola & $<3,0$ & $<3,0$ & Ausência & Ausência & $<100$ \\
\hline $\mathrm{F}$ & Caju & 9,2 & $<3,0$ & Ausência & Ausência & $4,2 \times 10^{3}$ \\
\hline $\mathrm{F}$ & Goiaba & $3,6 \times 10$ & $<3,0$ & Ausência & Ausência & $1,9 \times 10^{4}$ \\
\hline G & Acerola & $<3,0$ & $<3,0$ & Ausência & Ausência & $2,6 \times 10^{3}$ \\
\hline $\mathrm{G}$ & Caju & $1,1 \times 10^{3}$ & 9,2 & Ausência & Ausência & $8,2 \times 10^{4}$ \\
\hline $\mathrm{G}$ & Goiaba & $<3,0$ & $<3,0$ & Ausência & Ausência & $7,3 \times 10^{3}$ \\
\hline $\mathrm{H}$ & Acerola & $<3,0$ & $<3,0$ & Ausência & Ausência & $<100$ \\
\hline $\mathrm{H}$ & Caju & $<3,0$ & $<3,0$ & Ausência & Ausência & $<100$ \\
\hline $\mathrm{H}$ & Goiaba & $<3,0$ & $<3,0$ & Ausência & Ausência & $5,9 \times 10^{3}$ \\
\hline
\end{tabular}

Fonte: Elaborada pelo autor.

Nas amostras do Lote 2 (Tabela 2), 54\% das polpas de frutas não se enquadraram nos padrões estabelecidos para bolores e leveduras pela ANVISA (Brasil, 2019), e em 16,6\% foi detectada presença de E. coli. Contudo, não houve crescimento de Salmonella sp., estando esse resultado de acordo com a legislação vigente.

De acordo com o MAPA (Brasil, 2000), 20,83\% e 37,5 \% das amostras do Lote 2 não se apresentaram nos limites estabelecidos para coliformes termotolerantes e bolores e leveduras, respectivamente. Quinze amostras $(62,5 \%)$ apresentaram crescimento de bolores e leveduras, sendo a polpa de goiaba da marca $\mathrm{C}$ a que apresentou maior contaminação nas diferentes marcas. Além disso, 16,6\% apresentaram a presença de E. coli nas amostras de caju e goiaba, indicando más condições de higiene na elaboração dessas polpas. 
Tabela 2- Análises microbiológicas de polpas de frutas do Lote 2: coliformes totais, coliformes termotolerantes, pesquisa Escherichia coli, Salmonella sp, e bolores e leveduras.

\begin{tabular}{|c|c|c|c|c|c|c|}
\hline \multicolumn{7}{|c|}{ LOTE 2} \\
\hline Marca & Sabor & $\begin{array}{c}\text { Coliformes } \\
\text { totais } \\
\left(\mathrm{NMP} \mathrm{g}^{-1}\right)\end{array}$ & 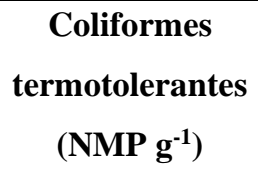 & $\begin{array}{c}\text { Pesquisa de } \\
\qquad \text { E. coli }\end{array}$ & Salmonella sp./25 g & $\begin{array}{l}\text { Bolores e } \\
\text { leveduras } \\
\left(\mathrm{UFC} \mathrm{g}^{-1}\right)\end{array}$ \\
\hline $\mathrm{A}$ & Acerola & $<3,0$ & $<3,0$ & Ausência & ausência & $1,48 \times 10^{4}$ \\
\hline A & Caju & $<3,0$ & $<3,0$ & Ausência & ausência & $<100$ \\
\hline A & Goiaba & $<3,0$ & $<3,0$ & Ausência & ausência & $1,6 \times 10^{4}$ \\
\hline B & Acerola & $<3,0$ & $<3,0$ & Ausência & ausência & $2,5 \times 10^{3}$ \\
\hline $\mathrm{B}$ & Caju & $<3,0$ & $<3,0$ & Ausência & ausência & $<100$ \\
\hline $\mathrm{B}$ & Goiaba & 9,2 & 9,2 & Presença & ausência & $2,3 \times 10^{3}$ \\
\hline $\mathrm{C}$ & Acerola & $<3,0$ & $<3,0$ & Ausência & ausência & $<100$ \\
\hline $\mathrm{C}$ & Caju & $2,3 \times 10$ & $2,3 \times 10$ & Presença & ausência & $<100$ \\
\hline $\mathrm{C}$ & Goiaba & $4,3 \times 10$ & $4,3 \times 10$ & Ausência & ausência & $6,7 \times 10^{4}$ \\
\hline $\mathrm{D}$ & Acerola & $<3,0$ & $<3,0$ & Ausência & ausência & $<100$ \\
\hline $\mathrm{D}$ & Caju & $<3,0$ & $<3,0$ & Ausência & ausência & $<100$ \\
\hline D & Goiaba & $<3,0$ & $<3,0$ & Ausência & ausência & $<100$ \\
\hline $\mathrm{E}$ & Acerola & $<3,0$ & $<3,0$ & Ausência & ausência & $5,3 \times 10^{3}$ \\
\hline $\mathrm{E}$ & Caju & $1,1 \times 10^{3}$ & $1,5 \times 10^{2}$ & Presença & ausência & $4,7 \times 10^{4}$ \\
\hline $\mathrm{E}$ & Goiaba & $1,1 \times 10^{3}$ & 3,6 & Presença & ausência & $1,3 \times 10^{4}$ \\
\hline $\mathrm{F}$ & Acerola & $<3,0$ & $<3,0$ & Ausência & ausência & $2,9 \times 10^{3}$ \\
\hline $\mathrm{F}$ & Caju & $<3,0$ & $<3,0$ & Ausência & ausência & $2,3 \times 10^{3}$ \\
\hline $\mathrm{F}$ & Goiaba & 9,2 & $<3,0$ & Ausência & ausência & $3 \times 10^{4}$ \\
\hline G & Acerola & $<3,0$ & $<3,0$ & Ausência & ausência & $<100$ \\
\hline $\mathrm{G}$ & Caju & $2,3 \times 10$ & $<3,0$ & Ausência & ausência & $1,9 \times 10^{4}$ \\
\hline G & Goiaba & $<3,0$ & $<3,0$ & Ausência & ausência & $<100$ \\
\hline $\mathrm{H}$ & Acerola & $<3,0$ & $<3,0$ & Ausência & ausência & $<100$ \\
\hline $\mathrm{H}$ & Caju & $<3,0$ & $<3,0$ & Ausência & ausência & $<100$ \\
\hline $\mathrm{H}$ & Goiaba & $<3,0$ & $<3,0$ & Ausência & ausência & $5,6 \times 10^{3}$ \\
\hline
\end{tabular}

Fonte: Elaborada pelo autor.

Silva et al. (2016), ao analisar 17 sabores de polpas de frutas de uma empresa durante três meses, detectaram elevada contaminação por fungos em 30\%, $10 \%$ e 32,5\% das amostras no primeiro, segundo e terceiro mês, respectivamente, mas para coliformes termotolerantes permaneceram de acordo com a legislação do MAPA.

Souza, Carneiro e Gonsalves (2011) analisaram 12 amostras diferentes de polpa de fruta congelada de uma única marca comercial, e obtiveram como resultado 50\% das amostras contaminadas para bolores e leveduras, e Salmonella sp. dentro dos limites estabelecidos pela legislação vigente da ANVISA.

Santos e Vieira (2020), avaliando a qualidade microbiológica de polpa de frutas artesanais produzidas e comercializadas nos mercados públicos de João Pessoa, encontraram a presença de E. coli em 6,25\% das amostras, valor 
inferior ao encontrado neste trabalho. A presença dessa bactéria patogênica pode ocasionar doenças no tubo digestivo, indicando um risco à saúde do consumidor.

Fechine Neto et al. (2016), avaliando o perfil microbiológico de polpas de frutas congeladas comercializadas na cidade de Missão Velha-CE, não detectou crescimento de coliformes totais e termotolerantes, mas três das 20 amostras analisadas excederam os padrões preconizados para bolores e leveduras. Os autores associaram esse resultado ao $\mathrm{pH}$ das frutas analisadas, por serem consideradas ácidas, não apresentando condições favoráveis para o crescimento de coliformes. Entretanto, bolores e leveduras crescem também em meio ácido.

Sebastiany, Rego e Vital (2009) observaram em seu estudo que as polpas de frutas não pasteurizadas de acerola, cupuaçu, goiaba e maracujá apresentaram maior índice de inadequação do que as polpas tratadas termicamente. Eles concluíram que a pasteurização confere maior segurança ao produto do que o simples congelamento. Isso corrobora com os resultados obtidos no presente estudo, no qual se avaliou polpas não pasteurizadas, que, em sua maioria, apresentaram crescimento de microrganismos.

Sousa et al. (2020), analisando polpas de frutas congeladas de acerola, cupuaçu e maracujá em Santarém-Pará, verificaram que todas as amostras avaliadas estavam dentro do limite estabelecido pela legislação, indicando aplicação de um eficiente controle de qualidade, resultado diferente ao encontrado neste estudo.

Silva et al. (2020), ao avaliar polpas de frutas de cupuaçu, graviola, manga, goiaba, acerola, maracujá, caju, muruci, abacaxi, açaí e cacau comercializadas em supermercado de Belém-PA, detectaram que 93,34\% das amostras se encontravam em conformidade para coliformes termotolerantes. Além disso, semelhante ao encontrado no presente estudo, $100 \%$ das amostras analisadas não apresentaram contaminação por Salmonella sp.

Pelo fato de as legislações estabelecerem padrões microbiológicos distintos, dependendo da legislação utilizada como referência, à avaliação microbiológica pode estar em acordo ou não com os parâmetros requeridos.

As polpas de frutas aqui analisadas apresentaram padrão de qualidade variável para os diferentes lotes, indicando não haver uma padronização da higienização e controle de qualidade da matéria-prima e preparação dos produtos. As exceções foram às polpas de frutas da marca $\mathrm{D}$, que foi a única marca que se enquadrou nos padrões estabelecidos tanto da ANVISA quanto do MAPA, não apresentando nenhum crescimento dos microrganismos descritos nas legislações, e, por isso, indicando ser produtos de qualidade e seguros para o consumidor. Além disso, não houve variação dos resultados entre os Lotes 1 e 2, mantendo uma padronização nos seus produtos.

As amostras que apresentaram seus parâmetros microbiológicos acima do exigido pelo MAPA e pela ANVISA indicam processamento inadequado, podendo ser a contaminação oriunda da matéria-prima, manipulador, equipamentos, ambiente (Silva et al., 2016). Destaca-se a presença de E. coli, uma bactéria considerada como importante indicador higiênicosanitário, em 16,6\% das amostras, inferindo que os manipuladores necessitam de um treinamento sobre as Boas Práticas de Fabricação durante o processamento na indústria para produzir um produto de qualidade e sem contaminação microbiana. Além disso, reforça-se que o crescimento de bolores e leveduras também indica contaminação devido ao desprovimento de um controle de qualidade eficiente.

\section{Análises microscópicas}

A Figura 1 apresenta os gráficos com os percentuais de matérias estranhas leves (a) e de matérias estranhas pesadas (b), associadas à densidade dos seus elementos, com base no meio de flutuação utilizado para a separação a partir da amostra.

Nas polpas de frutas analisadas não foi encontrado nenhum fragmento de insetos, pelos de animais ou humanos, areia e terra. 
Figura 1: Gráfico com o percentual de matérias estranhas leves (a) e matérias estranhas pesadas (b).

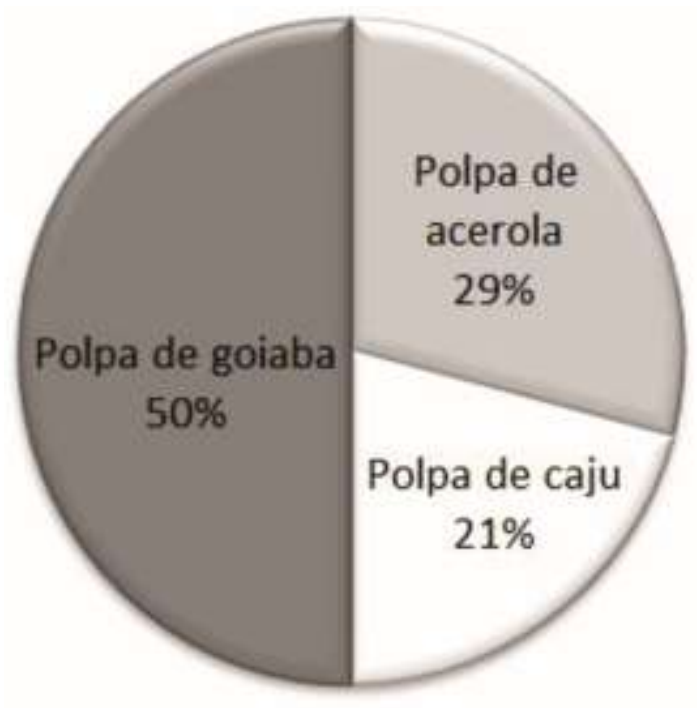

(a)

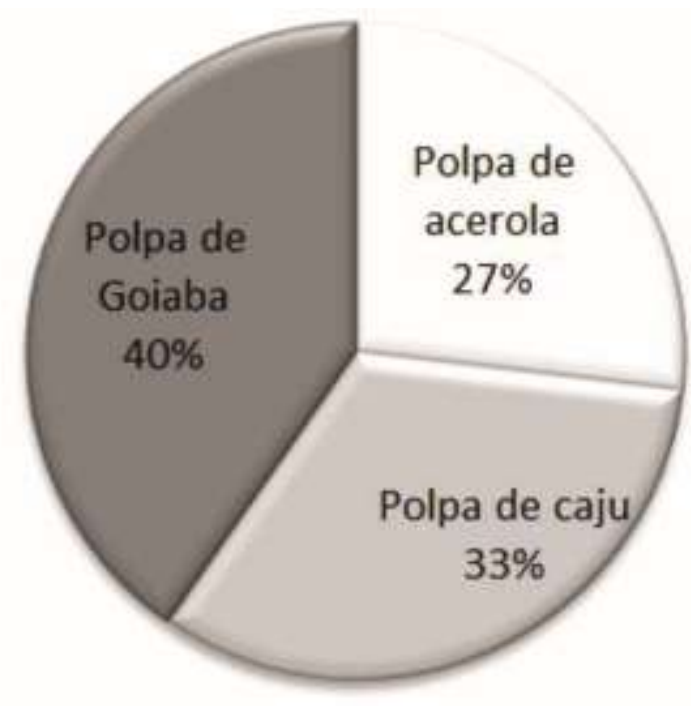

(b)

Fonte: Elaborada pelo autor.

Essas matérias estranhas encontradas podem estar associadas à seleção dos frutos após a colheita ou às más condições de higienização das instalações das indústrias. Por isso, a seleção dos frutos e sua higienização adequada garantem que no produto final não sejam encontradas partes não comestíveis ou qualquer matéria que possa estar presente durante a colheita, mas que não faça parte do fruto, como partes da planta, terra e insetos.

As matérias estranhas encontradas nas polpas de frutas aqui analisadas foram fragmentos de metal, plásticos coloridos e fio têxtil, como mostra a Figura 2. Essas sujidades são semelhantes às encontradas por Ramos (2004) ao pesquisar sujidades, também em polpas de frutas. Os fios encontrados se assemelham ao material das embalagens que são utilizadas para transportar frutas até a indústria. Durante o processamento dessas frutas pode ocorrer a contaminação das polpas com esse material.

Santos et al. (2020), no seu estudo também de avaliação de matéria estranha em polpas de frutas, encontrou que $72 \%$ das amostras investigadas apresentaram algum tipo de matéria estranha, como fragmento de inseto, parte não comestível do fruto, grãos de areia e sujidades, ao que eles correlacionaram à existência de falhas nas etapas de processamento das polpas de frutas, como seleção, lavagem da matéria-prima, manipulador não qualificado, transporte e comercialização incorretos do produto.

Bueno et al. (2002), durante análises microscópicas de 15 amostras diferentes de polpas de frutas de uma única marca comercial, obtiveram $60 \%$ das polpas com fragmentos ou larvas de insetos e ácaros, resultado este que foi relacionado ao fato de as frutas estarem sujeitas a contaminação por pragas. 
Figura 2- Matérias estranhas na polpa de acerola, goiaba e caju. A- Fio têxtil; B-fragmentos de plásticos coloridos; CFragmento de metal.
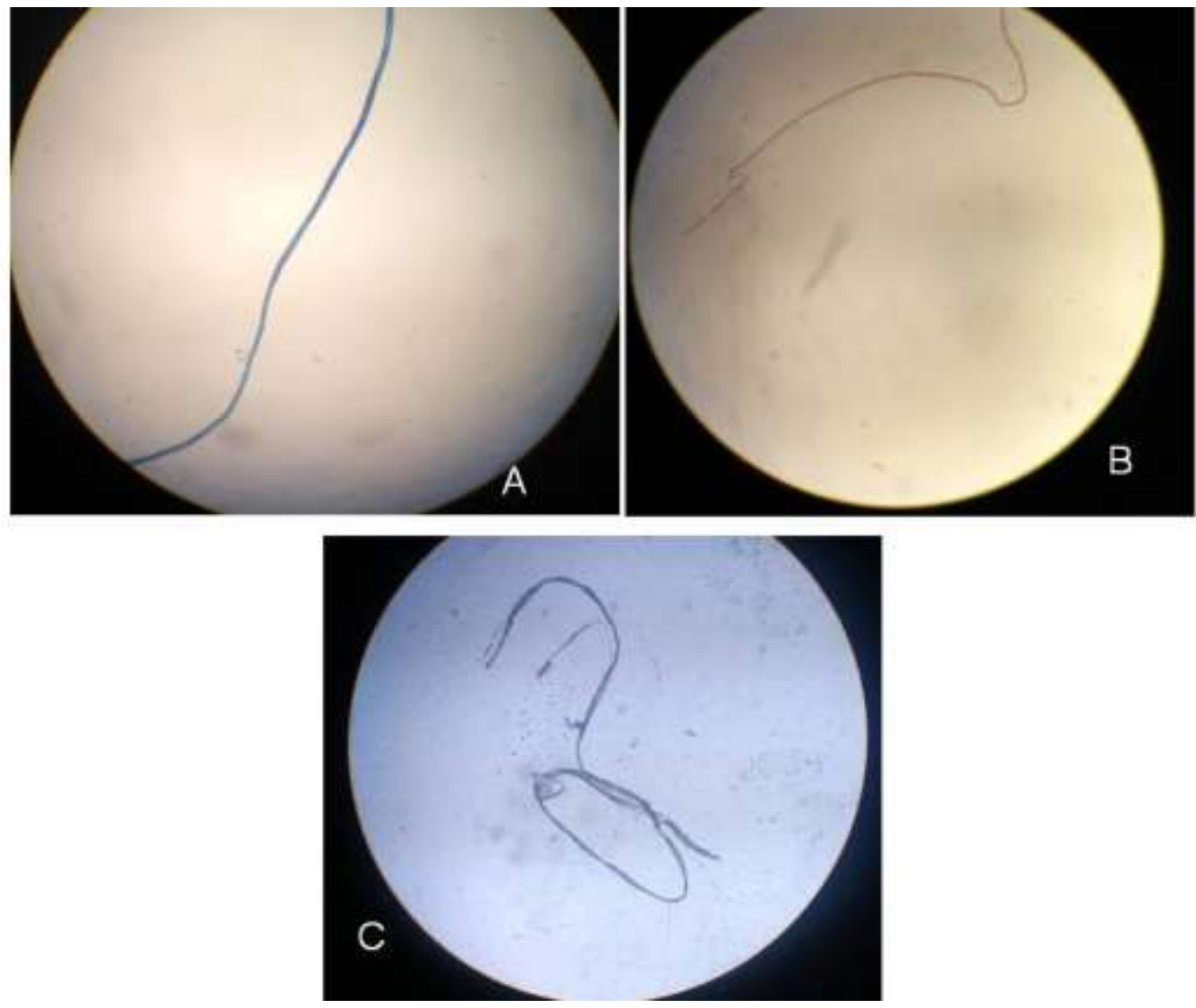

Fonte: Elaborada pelo autor.

Os resultados das análises microscópicas com a incidência de cada uma das matérias estranhas encontradas, por tipo de polpa processada, das diferentes marcas analisadas, se encontram na Tabela 3.

De acordo com o exigido na legislação (Brasil, 2002), polpas de frutas não devem conter terra, sujidades, parasitas, fragmento de insetos e pedaços não comestíveis da fruta ou planta.

Essas indústrias necessitam implantar padrões de higiene para a elaboração das polpas, desde a recepção da matériaprima até a expedição do produto, para garantir alimentos seguros e de qualidade aos consumidores, além de conscientizar todos os colaboradores sobre seu papel fundamental na garantia de um produto seguro. É de suma importância que todos da empresa estejam envolvidos no propósito da qualidade, que cada indústria tenha sua cultura de qualidade baseada na colaboração de todos para garantir que a missão principal do estabelecimento de oferecer um alimento seguro seja cumprida. 
Tabela 3: Incidência de sujidade por lote de polpas de acerola, caju e goiaba de oito diferentes marcas, em dois lotes.

\begin{tabular}{|c|c|c|c|c|c|c|c|c|c|c|}
\hline \multirow[t]{3}{*}{ Sabor } & \multirow{3}{*}{$\begin{array}{l}\text { Tipo de } \\
\text { sujidade }\end{array}$} & \multirow{3}{*}{ Lote } & \multicolumn{8}{|c|}{ Quantidade de sujidades } \\
\hline & & & & & & & & & & \\
\hline & & & $\mathbf{A}$ & $\mathbf{B}$ & $\mathrm{C}$ & $\mathbf{D}$ & $\mathbf{E}$ & $\mathbf{F}$ & G & $\mathbf{H}$ \\
\hline \multirow{5}{*}{ 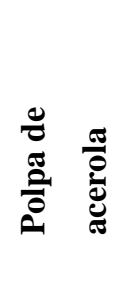 } & Matéria & 1 & 0 & 2 & 0 & 1 & 0 & 1 & 1 & 0 \\
\hline & Leve & 2 & 0 & 0 & 0 & 0 & 0 & 0 & 2 & 0 \\
\hline & Matéria & 1 & 1 & 2 & 2 & 2 & 0 & 1 & 2 & 0 \\
\hline & Pesada & 2 & 0 & 3 & 2 & 2 & 0 & 1 & 0 & 0 \\
\hline & Matéria & 1 & 0 & 1 & 0 & 2 & 0 & 0 & 0 & 0 \\
\hline \multirow{3}{*}{ 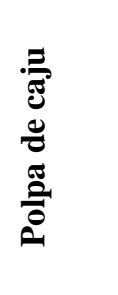 } & Leve & 2 & 0 & 0 & 0 & 0 & 0 & 2 & 0 & 0 \\
\hline & Matéria & 1 & 2 & 7 & 0 & 0 & 0 & 0 & 0 & 0 \\
\hline & Pesada & 2 & 1 & 0 & 1 & 10 & 0 & 1 & 0 & 0 \\
\hline \multirow{4}{*}{ 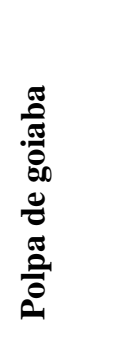 } & Matéria & 1 & 2 & 1 & 0 & 3 & 0 & 0 & 0 & 0 \\
\hline & Leve & 2 & 1 & 3 & 0 & 2 & 0 & 0 & 0 & 0 \\
\hline & Matéria & 1 & 5 & 1 & 0 & 7 & 0 & 4 & 0 & 0 \\
\hline & Pesada & 2 & 2 & 3 & 2 & 3 & 0 & 0 & 0 & 0 \\
\hline
\end{tabular}

Fonte: Elaborada pelo autor.

As quantidades de matéria estranha encontradas variaram de acordo com a marca, o sabor e o lote da polpa. A polpa de goiaba a foi que apresentou maior quantidade de matéria estranha leve, assim como de matéria pesada.

As marcas E e H não apresentaram nenhuma sujidade. Já as marcas B e D apresentaram maior quantidade. Mas esses dados divergem do resultado das análises microbiológicas, pois nas polpas da marca D não houve crescimento microbiano, enquanto nos produtos das marcas $\mathrm{E}$ e $\mathrm{H}$ verificou-se crescimento microbiano. Além disso, elas não foram tratadas termicamente por pasteurização para destruir os microrganismos patogênicos.

Assim, as polpas analisadas estão de acordo com a RDC 352 (Brasil, 2002), pois em nenhuma polpa de fruta foram encontrados fragmentos de insetos ou sujidades como areia, poeira, pedaços de plantas ou pedaços de vidro, ou seja, matérias estranhas que podem trazer risco à saúde do consumidor. Os materiais encontrados nesse estudo podem ser inerentes às embalagens das frutas, requerendo que os manipuladores tenham atenção no momento de retirar as frutas dessas embalagens.

\section{Conclusão}

Conclui-se que as polpas de frutas analisadas não estavam de acordo com a legislação vigente em todos os parâmetros microbiológicos exigidos para coliformes termotolerantes, E. coli ou bolores e leveduras. A marca D foi a única em que não houve crescimento microbiano em nenhum dos lotes. 
Apenas uma marca indicou eficiente controle de qualidade, por não ter apresentado nenhum crescimento microbiano. Dentre todas as amostras, $87,5 \%$ estavam em desacordo com a legislação vigente com algum padrão exigido acima do limite permitido.

As polpas mostraram adequação quanto à legislação que estabelece os padrões microscópicos, pois não foi encontrado nenhum fragmento de inseto, larvas, areia ou partes não comestíveis das frutas. As únicas matérias estranhas encontradas foram pequenos fios semelhantes a plástico, metal e de origem têxtil.

Sugere-se como estudos futuros, a realização análises morfológicas e histológicas nos fragmentos encontrados para confirmação do tipo de perigo e maior possibilidade de identificação da sua origem.

\section{Referências}

Association of Official Analytical Chemists - AOAC. (2007). Official Methods of Analysis of AOAC International. (18th ed.). Gaithersburg, MD, USA: AOAC International.

Brasil. (2000). Instrução Normativa $n^{o}$ 01/00, de 07/01/2000. Regulamento técnico geral para fixação dos padrões de identidade e qualidade para polpa de fruta. Diário Oficial da República Federativa do Brasil, Brasília, DF, Seção I, p.54-58.

Brasil. (2002). Resolução RDC ANVISA/MS N 352, de 23 de dezembro de 2002. Regulamento técnico de boas práticas de fabricação para estabelecimentos produtores/industrializadores de frutas e/ou hortaliças em conserva e a lista de verificação das boas práticas de fabricação para estabelecimento produtores/industrializadores de frutas e/ou hortaliças em conserva. Diário Oficial da União, Brasília, DF, Seção 1.

Brasil. (2014). Resolução RDC $N^{\circ}$ 14, de 28 de março de 2014, da Agência Nacional de Vigilância Sanitária. Dispõe sobre matérias estranhas macroscópicas e microscópicas em alimentos e bebidas, seus limites de tolerância e dá outras providências. Diário Oficial da República Federativa do Brasil, Brasília, DF, Seção 1, p.45-53.

Brasil. (2019). Resolução RDC N $N^{\circ}$ 331, de 23 de dezembro de 2019, da Agência Nacional de Vigilância Sanitária. Dispõe sobre os padrões microbiológicos de alimentos e sua aplicação. Diário Oficial da República Federativa do Brasil, Brasília, Seção 1, 26 dez. Seção 1, p.96.

Brasil. (2019). Instrução Normativa $N^{\circ}$ 60, de 23 de dezembro de 2019, da Agência Nacional de Vigilância Sanitária. Estabelece as listas de padrões microbiológicos para alimentos. Diário Oficial da República Federativa do Brasil, Brasília, DF, Seção 1, p.96.

Bueno, S. M., Lopes, M. R. V., Graciano, R. A. S., Fernandes, E. C. B., \& Garcia-Cruz, C. H. (2002). Avaliação da qualidade de polpas de frutas congeladas. Revista Instituto Adolfo Lutz, 2 (61), 121-126.

Food and Agriculture Organization - FAO. FAOSTAT - Food and agriculture data. (2018). http://www.fao.org/faostat/en/\#home

Franco, B. D. G. M., \& Landgraf, M. (2003). Microbiologia dos alimentos: Atheneu.

Fechine Neto, J. L., Calou, V. C. R., Silva, J. R. A., \& Mendes, R. C. (2016). Perfil microbiológico de amostras de polpas de frutas congeladas, comercializadas na cidade de Missão Velha-CE. Caderno de Cultura e Ciência, 15 (1), 37-56.

GIL, A. C. (2002). Como elaborar projetos de pesquisa: Atlas S. A., p. 176.

Pereira, J. M. A. T. K., Oliveira, K. A. M., Soares, N. F. F., Gonçalves, M. P. J. C., Pinto, C. L. O., \& Fontes, E. A. F. Avaliação da qualidade físico-química, microbiológica e microscópica de polpas de frutas congeladas comercializadas na cidade de Viçosa-MG. Alimentos e Nutrição Araraquara, 17 (4), $437-442$.

Ramos, M. E. C. (2004). Sujidades em polpa de frutas congeladas produzidas em Petrolina-PE e Juazeiro-BA. Dissertação (Mestrado) - Curso de Ciência dos Alimentos, Universidade Federal do Pernambuco.

Santos, R. E., \& Vieira, P. P. F. (2020). Avaliação da qualidade microbiológica de polpas de frutas artesanais produzidas e comercializadas nos mercados públicos do município de João Pessoa. Brazilian Journal of Development, 6 (9), 72847-72857.

Santos, V. M., Lima, G. S., Valencia, M. S., Salgado, S. M., \& Xavier, V. L. (2020). Qualidade físico-química, microbiológica e microscópica de polpas de frutas congeladas comercializadas na cidade de Recife, Pernambuco. Journal of Applied Pharmaceutical Sciences, 7, 26-41.

Sesbatiany, E., Rego, E. R., \& Vital, M. J. S. (2009). Qualidade microbiológica de polpas de frutas congeladas. Revista Instituto Adolfo Lutz, 2 (68), $224-231$.

Silva, C. E. F., Moura, E. M. O., Andrade, F. P., Gois, N. S. B., Silva, I. C. C., Silva, L. M. O., Souza, J. E. A., \& Abud, A. K. S. (2016). The Importance of monitoring the identity and quality standards in fruit pulp industry. Journal of Bioenergy and Food Science, 3 (1), 17-27

Silva, N., Junqueira, V. C. A., Silveira, N. F. A., Taniwaki, M. H., Gomes, R. A. R., \& Okazaki, M. M. (2017). Manual de métodos de análise microbiológica de alimentos: Blucher.

Silva, T. B. D., Martins, V. S., Pereira, J. M. C., BrasiL, L. S. N. S., \& Silva, S. M. R. (2020). Análise microbiológica de polpas de frutas industrializadas comercializadas em supermercado em Belém do Pará. Revista Univap, 26 (50), 36-46.

Sousa, Y. A., Borges, M. A., Viana, A. F. S., Dias, A. L., Sousa, J. J. V., Silva, B. A., Silva, S. K. R., \& Aguiar, F. S. (2020). Avaliação físico-química e microbiológica de polpas de frutas congeladas comercializadas em Santarém-PA. Brazilian Journal of Food Technology, 23, e2018085. 
Research, Society and Development, v. 10, n. 8, e23410817279, 2021

(CC BY 4.0) | ISSN 2525-3409 | DOI: http://dx.doi.org/10.33448/rsd-v10i8.17279

Souza, G. C., Carneiro, J. G., \& Gonsalves, H. R. O. (2011). Qualidade microbiológica de polpas de frutas congeladas produzidas no município de Russas-CE. Agropecuária Científica no Semi-Árido, 7 (3), 01-05.

Ziobro, G. C. Extraneous materials: isolation. In: Howirtz, W. (2000). Official methods of analysis of AOAC international. Arlington: AOAC, 16, 1-76. 